\title{
Bortezomib/Cyclophosphamide/Dexamethasone Regimen
}

National Cancer Institute

\section{Source}

National Cancer Institute. Bortezomib/Cyclophosphamide/Dexamethasone Regimen.

NCI Thesaurus. Code C113826.

A treatment regimen consisting of a combination of bortezomib, cyclophosphamide and dexamethasone. 